\title{
EFFECTS OF DIFFERENT BIOCHARS AMMENDMENTS ON PHYSIOCHEMICAL PROPERTIES OF SOIL AND ROOT MORPHOLOGICAL ATTRIBUTES OF FOKENIA HODGINSII (FUJIAN CYPRESS)
}

\author{
TARIN, M. W. K. ${ }^{1}$ - FAN, L. L. ${ }^{1}-$ SHEN, L. ${ }^{1}-$ LAI, J. L. ${ }^{1}-$ TAYYAB, M. ${ }^{2}-$ SARFRAZ, R. ${ }^{2}-$ CHEN, \\ L. Y. ${ }^{3}-$ Ye, J. ${ }^{3}-$ HE, T. Y. ${ }^{3}-$ RONG, J. D. ${ }^{1}-$ CHEN, L.G. ${ }^{1}-$ ZHENG, Y. S. ${ }^{1,3^{*}}$ \\ ${ }^{1}$ College of Forestry, Fujian Agriculture and Forestry University \\ Fuzhou, Fujian 350002, People's Republic of China \\ ${ }^{2}$ Fujian Agriculture and Forestry University, Fuzhou 350002, China \\ ${ }^{3}$ College of Arts \& College of Landscape Architecture, Fujian Agriculture and Forestry \\ University, Fuzhou, Fujian 350002, People's Republic of China \\ *Corresponding author \\ e-mail: zys1960@163.com; phone: +86-50-397-265 \\ (Received $4^{\text {th }}$ Apr 2019; accepted $13^{\text {th }}$ Jun 2019)
}

\begin{abstract}
Biochar (BC) is the carbon-rich material, increasingly as a soil additive for carbon sequestration and soil improvement. Various studies have shown that BC have a profound effect on root morphological traits on agricultural systems, however the effect of $\mathrm{BC}$ amendments on the root traits of forest species is scant. The current study attempts to evaluate the effects of different BCs as a soil amendment on the growth and root morphological traits of Fokienia hodginsii. For that reason, three different types of BCs; bamboo (BB), hardwood (BH), and rice straw (BR) with four levels $(0,5,20$, and $80 \mathrm{~g} \mathrm{~kg}^{-1}$ of soil) collectively ten treatment combination including control (Bo) were incorporated to soil and seedlings were allowed to grow in pots in greenhouse for one year. After one year uprooted seedlings roots were scanned and analyzed by using WinRHIZO software for comparison. Bamboo and rice straw $\mathrm{BC}$ amendments were found to significantly improve root traits particularly root volume, average diameter, and root length compared to Bo. Additionally, the seedlings treated with BR80, BB80, and BH80 attained 36\%, 29\%, and 25\% biomass, respectively compared to Control (Bo). Soil physiochemical properties particularly soil $\mathrm{pH}$ also varied between different $\mathrm{BCs}$ types and levels. Consequently, BC alkalinity is an important feature to correct soil acidity and improve soil fertility by altering soil nutrient content. Root establishment in acidic soils can be enhanced by BC amendments but selection of $\mathrm{BC}$ and soil is crucial to maximizing soil improvement and seedlings roots traits.
\end{abstract}

Keywords: Fokienia hodginsii, root traits, biomass, winRHIZO, alkalinity, soil improvement

\section{Introduction}

Fokenia hodginsii (Fujian cypress) is an important conifer; native to China and Vietnam. Currently, on the basis of its distribution, this conifer is globally threatened, protected species (B2/second degree) in China, and as vulnerable in red list of threatened species; generated by international union for conservation of nature (IUCN) (Luu and Thomas, 2000; Ding et al., 2017; Tarin et al., 2019). Timber of this conifer is valuable because of its straight grain and different aroma and is also being exported to Europe and elsewhere in Asia (Osborn, 2004). Moreover, siam-wood essential oil or pemou oil is extracted from its stumps and roots which contains high sesquiterpene content; which can sanitize and purify the air, kill bacteria, and resist insects. Furthermore, extract oil can be used to improve emotional balance and the mental clarity in aromatherapy (Paluch, 2009). As a result of, certain increase in human 
population has put enormous pressure on this conifer community by over logging for utilization of timber wood (Nguyen et al., 2015; Tarin et al., 2017). These anthropogenic (human activities) and pedogenic or natural factors (parent material) has resulted infertile soils (Lal, 2015). Consequently, high rates of deforestation, rise in global temperature (approximately $0.85 \pm 0.20^{\circ} \mathrm{C}$ ) during last 130 years will lead to unfavorable and harsh conditions for plants such as drought and flood etc. globally (Alexander et al., 2006; Tarin et al., 2019) Additionally, intensive forest management for conversion of natural forests into artificial plantations has been shown to deteriorate the soil physical health, like, reducing $\mathrm{pH}$ and porosity, and increasing bulk density (Tonks et al., 2017).

Global climate change and intensive forest management both have adversely affected the features of forest soils via decrease in soil organic carbon, acidification, biological properties, and biodiversity ( $\mathrm{Li}$ et al., 2018). Vast areas of tropical and subtropical regions of Southern China, soils are acidic where; soil fertility is the major constraint to plant growth (Haynes and Mokolobate, 2001; Baquy et al., 2017). However, mineral lime has been conventionally used to raise the soil pH (Adams, 1984) nevertheless, because of its high costs, much attention has been given to replacements like incorporation of crop straw in soil which also can increase soil $\mathrm{pH}(\mathrm{Xu}$ and Coventry, 2003). Besides, direct addition of such plant residues into the soils do not stay longer because of decomposition (Yuan and Xu, 2011). Recently, biochar (BC) has received much attention as an alternate to these soil organic amendments and is considered as a potential fertilizer due to partial combustion of several organic components. It has mostly alkaline nature subject to pyrolysis temperature over $400^{\circ} \mathrm{C}$ (Gaskin et al., 2008) and can raise the $\mathrm{pH}$ of acidic soils by decreasing exchangeable $\mathrm{Al}$ from soil (Chan et al., 2008b). Its amendments into the soil can improve soil fertility (Topoliantz et al., 2005), stimulate the plant growth (Jeffery et al., 2011a) and enhance the sequestration of $\mathrm{CO}_{2}$ from the atmosphere (Lehmann et al., 2006).

Numerous studies on agriculture and horticulral system have been shown to examine, how BC effects on plant growth and root morphological parameters. Inappropriately, research on effects of $\mathrm{BCs}$ amendments on growth of trees particularly on root morphological parameters is rare. BC application into the soil has significant effects on growth and root morphology as plant roots contact directly to its particles for uptake of soil nutrients and water (Prendergast-Miller et al., 2014). Therefore, measurement of roots morphological parameters, such as root length, root diameters etc. are essential to understand plant physiological functions. It is necessary to determine how root morphological traits respond to different BC application under multiple levels for better management of forest species.

In the context of previous studies, responses of root traits like root morphology and biomass (Brennan et al., 2014; Keith et al., 2015), root-associated microbes, and nutrient concentration (Rillig et al., 2010; Vanek and Lehmann, 2015) can be influenced by incorporation of BCs. Moreover, root morphological traits play diversified roles in plant growth and development (Nie et al., 2013). For instance, root length is possibly one of the important parameter, mainly because of general indicator of plant response to environmental factors and also controls the acquisition of nutrients or water (Clothier and Green, 1997; Edwards et al., 2004) whereas for the biomass increase, root diameter is considered as beneficial (Eissenstat and Yanai, 1997). To date, BC effects on root morphological traits are highly variable and controversial. For instance, because of various factors, root biomass remains relatively stable, decrease or increase under BCs 
application (Macdonald et al., 2014; Prendergast-Miller et al., 2014; van de Voorde et al., 2014). The BC type (different materials or pyrolysis temperature) is an important factor because it varies significantly in chemical composition and $\mathrm{pH}$ (Lehmann et al., 2011). Consequently, the variation in characteristics of BCs and their application rate may also influence the soil physiochemical properties and ultimately alter the root morphological traits (Reibe et al., 2015; Reverchon et al., 2014). For that reason, it is important to know how root traits respond under different $\mathrm{BCs}$ application. In the current study, it was hypothesized that addition of $\mathrm{BC}$ into the soil may affect the biomass and root traits of the $F$. hodginsii seedlings by improving the soil physiochemical properties. Therefore, one year pot experiment was conducted to examine the effects of three different BCs under four levels (i) to identify the effects of different BCs on the physiochemical properties of soil, (ii) to investigate the effects of different $\mathrm{BCs}$ on growth (biomass) of $F$. hodginsii seedlings, and root morphological traits.

\section{Material and methods}

\section{Study area and design}

The present study was started in March, 2017 at Bamboo Institute of Fujian Agriculture and Forestry University Fuzhou, Fujian Province, P. R. China (lat. $26^{\circ} 5^{\prime}$ N, long. $119^{\circ} 13^{\prime}$ E, elevation 12 m; Fig. 1).

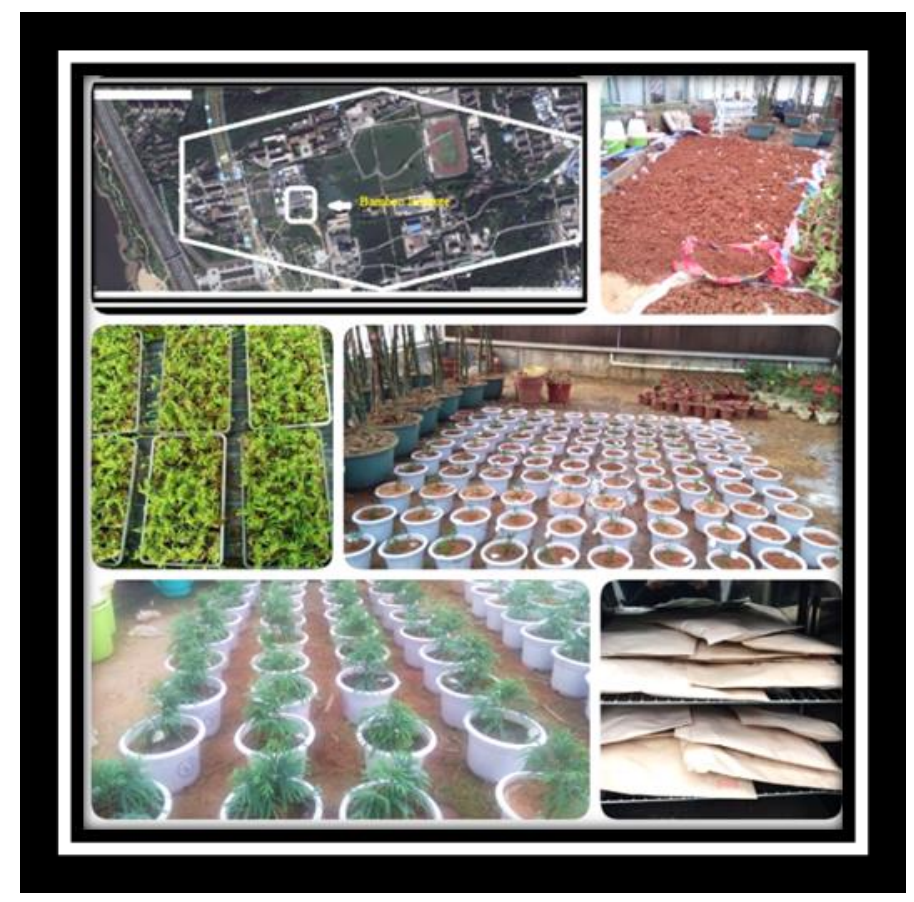

Figure 1. Boundary of Fujian Agriculture and Forestry University (Bamboo Institute), experimental design and order

The metrological informations of the study site during the entire experiment period are presented in App. 1. Three different types of commercial biochars (BCs); bamboo 
biochar $\left(\mathrm{BB}\right.$, produced at $\left.450^{\circ} \mathrm{C}\right)$, hardwood biochar $\left(\mathrm{BH}\right.$, produced at $\left.420^{\circ} \mathrm{C}\right)$, and rice straw biochar $\left(\mathrm{BR}\right.$, produced at $\left.500^{\circ} \mathrm{C}\right)$ were used; which were purchased from Nanjing Qinfeng Straw Technology Co. Ltd. China. Before application to soil the physiochemical characteristics of these BCs and basic soil were determined (Table 1).

Table 1. Physiochemical properties of BCs and soil used in the experiment, BB: bamboo biochar

\begin{tabular}{c|c|c|c|c}
\hline Characteristics & BB & BH & BR & Basic soil \\
\hline $\mathrm{pH}$ & 9.687 & 5.703 & 9.833 & 4.685 \\
$\mathrm{EC}\left(\mathrm{m} \mathrm{Scm}^{-1}\right)$ & 3.140 & 6.343 & 4.070 & 106.667 \\
$\mathrm{TC}\left(\mathrm{g} \mathrm{Kg}^{-1}\right)$ & 311.220 & 330.530 & 250.053 & 3.358 \\
$\mathrm{OM}\left(\mathrm{g} \mathrm{Kg}^{-1}\right)$ & 536.543 & 569.834 & 431.092 & 5.790 \\
$\mathrm{TN}\left(\mathrm{g} \mathrm{Kg}^{-1}\right)$ & 6.243 & 8.297 & 5.153 & 0.497 \\
$\mathrm{AP}\left(\mathrm{mg} \mathrm{Kg}^{-1}\right)$ & 32.381 & 24.318 & 29.076 & 10.245 \\
$\mathrm{TP}\left(\mathrm{g} \mathrm{Kg}^{-1}\right)$ & 0.399 & 0.296 & 0.311 & 0.256 \\
Ext. K $\left(\mathrm{g} \mathrm{Kg}^{-1}\right)$ & 0.335 & 0.321 & 0.371 & 0.356 \\
$\mathrm{C}: \mathrm{N} \mathrm{Ratio}$ & 49.975 & 39.846 & 48.641 & 6.864 \\
\hline
\end{tabular}

BB; Bamboo biochar, BH: hardwood Biochar, BR, rice straw biochar TN: total nitrogen, TC: total carbon, TP: total phosphorus, AP: available phosphorus, OM: organic matter, Ext. K: extractable potassium, C: N: carbon nitrogen ratio

These three BCs were incorporated to soil with four different levels; 0, 5, 20, and 80 $\mathrm{g} \mathrm{kg}^{-1}$ of soil (Tarin et al., 2019). One-year old seedlings of $F$. hodginsii (uniform size) were collected from forest nursery (Anxi County, Fujian, China), transplanted to poly vinyl pots (height $=18 \mathrm{~cm}$, top circumference $=62 \mathrm{~cm}$, bottom circumference $=52 \mathrm{~cm}$, $\mathrm{d}=22 \mathrm{~cm}$ ), and established in greenhouse in completely randomized design (four replication) for one year till the end of March, 2018. These seedlings were allowed to grow under greenhouse condition (natural light) and usual irrigation practice in order to produce healthy seedlings (Wang et al., 2014; Razaq et al., 2017). Additionally, after 15 days of establishment, all the seedlings were treated $10 \mathrm{~g}$ each pot with NPK fertilizer (Tarin et al., 2019). After one year; March 2018, seedlings were uprooted to determine plant fresh/dry weights and morphological parameters of roots.

\section{Determination of physiochemical properties of soil}

To determine the soil physiochemical properties, all the analysis were conducted in the Bamboo Institute, College of Forestry, Fujian Agriculture and Forestry University, China. At the start of the experiment (March, 2017), physiochemical properties of soil and all three types of BCs were assessed (Table 1). After one year, at the end of experiment (March, 2018), soil samples from 0-15 cm depth from each replicates were collected, mixed to produce composite samples and were sealed in clean, air-tight polythene bags. Four samples from each treatments were air-dried and then passed through a 2-mm/0.149-mm mesh to assess the physiochemical properties of soil. Soil $\mathrm{pH}$ (1:2.5 soil/water suspensions) was measured by using glass electrode meter as described by Tarin et al. (2019). Elemental analyzer (Thermo Scientific ${ }^{\mathrm{TM}}$, Waltham, MA, USA) was used for determination of soil Total $\mathrm{N}$ and $\mathrm{C}$ (Carbon) and then calculated as organic matter (OM), whereas for determination of total Phosphorus (TP) and available Phosphorus (AP) alkali fusion-Mo-Sb anti-colorimetry method as described by Sarfraz et al. (2019). Ammonium acetate solution was used for the measurement of extractable Potassium (ext. K) (Pansu and Gautheyrou, 2007). 


\section{Biomass and morphological parameters}

Above ground morphological parameters like plant height and basal diameters of seedlings were measured by using the ordinary measuring tape $(\mathrm{cm})$ and vernier caliper $(\mathrm{mm})$, respectively. Whereas for biomass determination, seedlings were uprooted from pots with intensive care to avoid any damage to the roots, washed with deionized water and similarly, for roots morphological traits, root samples were carefully taken in each treatment, using the procedure described by Guo et al. (2008). The root samples were scanned with Expression 10000XL 1.0 scanner (dpi = 400; Epson Telford, Ltd., Telford, UK). Finally, the seedlings were oven dried to constant mass at $65^{\circ} \mathrm{C}$, in order to determine dry mass. Later the images of roots were analyzed by using WinRHIZO (Pro2004b) software (Instruments Regent Co., Ville de Québec, QC, Canada) in order to determine the root surface area, root volume, total root length, and average root diameter.

\section{Statistical analysis}

Data was statistically analyzed with SPSS-19 statistical software. All the data were expressed as means and standard errors (SE) with four replications. Comparisons of different means were analyzed by Duncan's multiple range tests; $\alpha 0.05$ probability level. For tables and figures Origin lab 8.5 and Microsoft excels were used.

\section{Results}

\section{Effects of biochar amendments on physiochemical properties of soil}

At the final harvest, soil nutrient dynamics under different BCs amended treatments were changed (Fig. 2). The change in soil $\mathrm{pH}$ after one-year under different BCs (BB, $\mathrm{BH}$, and BR) incorporated samples is shown in Figure $2 a$.
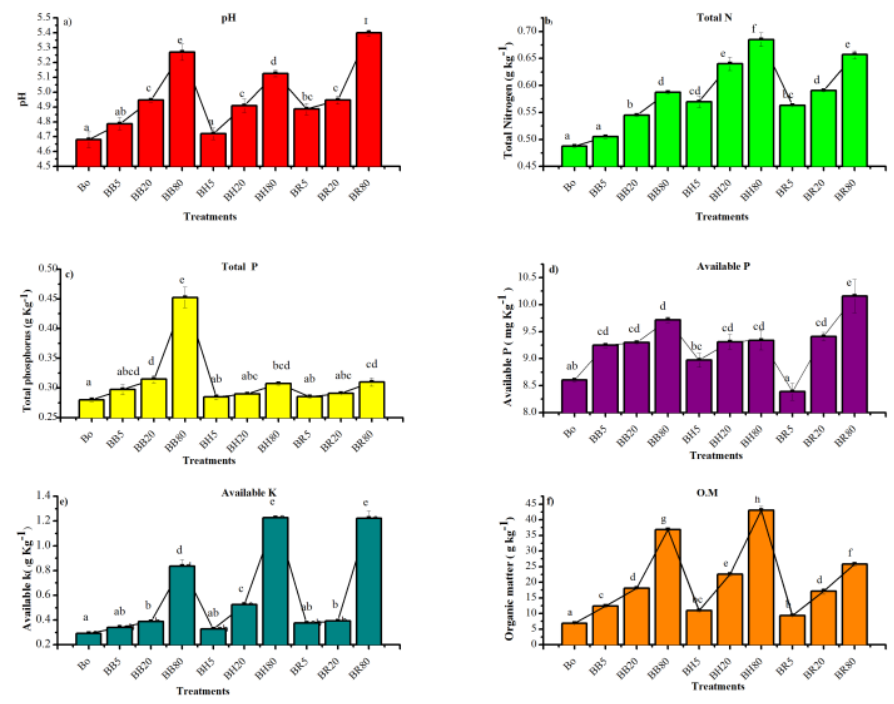

Figure 2. Comparison of soil physiochemical properties under different biochars amendments. Treatments include; control as Bo, bamboo biochar as (BB; 5, 20 and 80 representing different doses $\mathrm{g} \mathrm{kg}^{-1}$ of soil), hardwood biochar as (BH; 5, 20 and 80 representing different doses $\mathrm{g} \mathrm{kg}^{-1}$ of soil), rice straw biochar as (BR; 5, 20 and 80 representing different doses $\mathrm{g} \mathrm{kg}^{-1}$ of soil).

Different letters indicate significant difference $(P \leq 0.05)$ among different treatments with error bars 
The liming effects of $\mathrm{BB}$ and $\mathrm{BR}$ were significant for rising soil $\mathrm{pH}(P \leq 0.05)$ as compared to $\mathrm{BH}$. All BCs amended soil presented higher macronutrients (NPK) concentrations compared to Bo. Available P concentrations were significantly higher under BR80 compared to all other treatments, whereas total $\mathrm{N}$ concentration was highest in BH80. Overall, the concentrations of macro-nutrients increased under higher doses of $\mathrm{BCs}$ depending upon their type. Total $\mathrm{N}$, Total $\mathrm{P}$, available $\mathrm{P}$, extractable $\mathrm{K}$, and organic matter showed significant difference than that of Bo.

\section{Effects of biochar amendments on biomass and morphological parameters of seedling}

Application of BC significantly increased the morphological parameters of the seedlings. Figure 3 shows the complete comparison of treatments combination for above and below ground attributes.

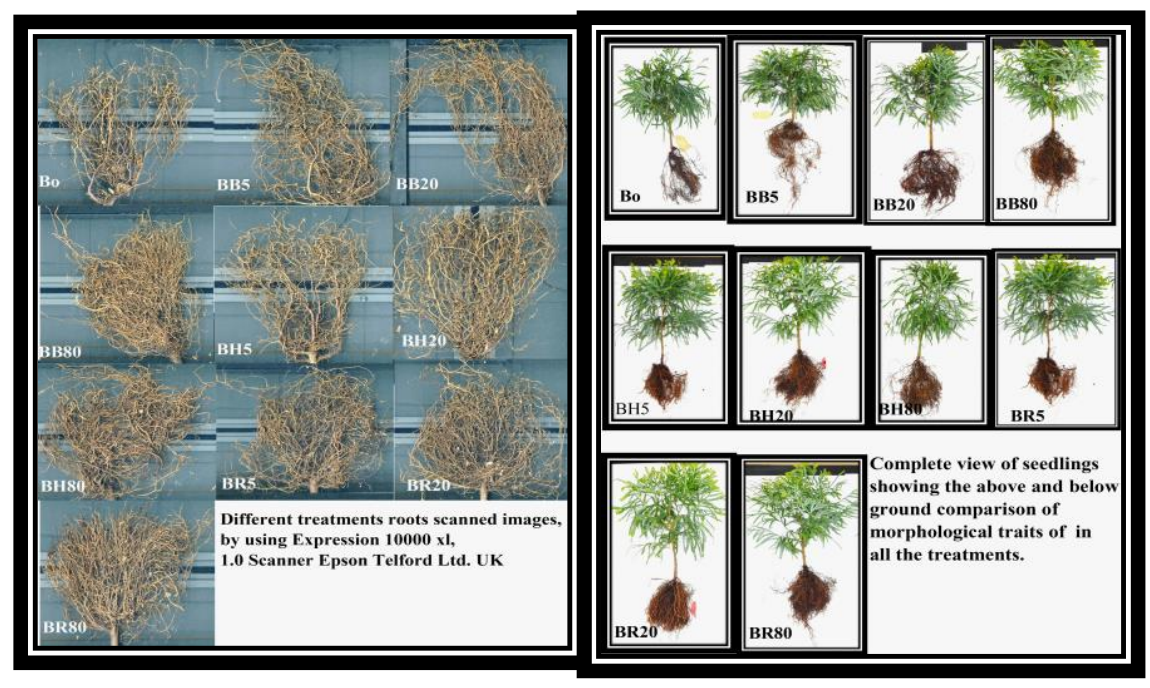

Figure 3. Complete view of seedlings showing the above and below ground comparison of morphological traits for all the treatments.

Treatments include; control as Bo, bamboo biochar as (BB; 5, 20 and 80 representing different doses $\mathrm{g} \mathrm{kg}^{-1}$ of soil), hardwood biochar as (BH; 5, 20 and 80 representing different doses $\mathrm{g} \mathrm{kg}^{-1}$ of soil), rice straw biochar as (BR; 5, 20 and 80 representing different doses $\mathrm{g} \mathrm{kg}^{-1}$ of soil)

Our results showed that BCs application increased the plant height, particularly seedlings treated with $\mathrm{BB} 20, \mathrm{BH} 20$ and BR20 were taller and showed significant difference than that of Bo (Fig. 4a). Moreover, within different BCs treatments, no significant difference was observed for seedlings basal diameter except BR80 amendments (Fig. 4b). Under different BC amendments, biomass of seedlings, treated with BB80, BH20, BH80, BR20, and BR80 were significantly increased than that of Bo (Fig. 4c). Likewise, for dry weight, seedlings treated with BB20, BB80, BR20, and BR80 showed significant differences compared to Bo (Fig. 4d).

\section{Effects of biochar amendments on root morphological traits}

Results from the current study suggested that BC amendment promoted the morphological traits of the roots. Under different BC types and levels, the roots morphological characteristics varied in terms of root volume, surface area, diameter, and length. BC application significantly $(P \leq 0.05)$ increased root volume in all the BCs 
treated seedlings except BH5 and BR5 as compared to Bo. For all BCs treatment combinations, highest root volume was observed in seedlings treated with BB80 and BR80 (Fig. 5a).

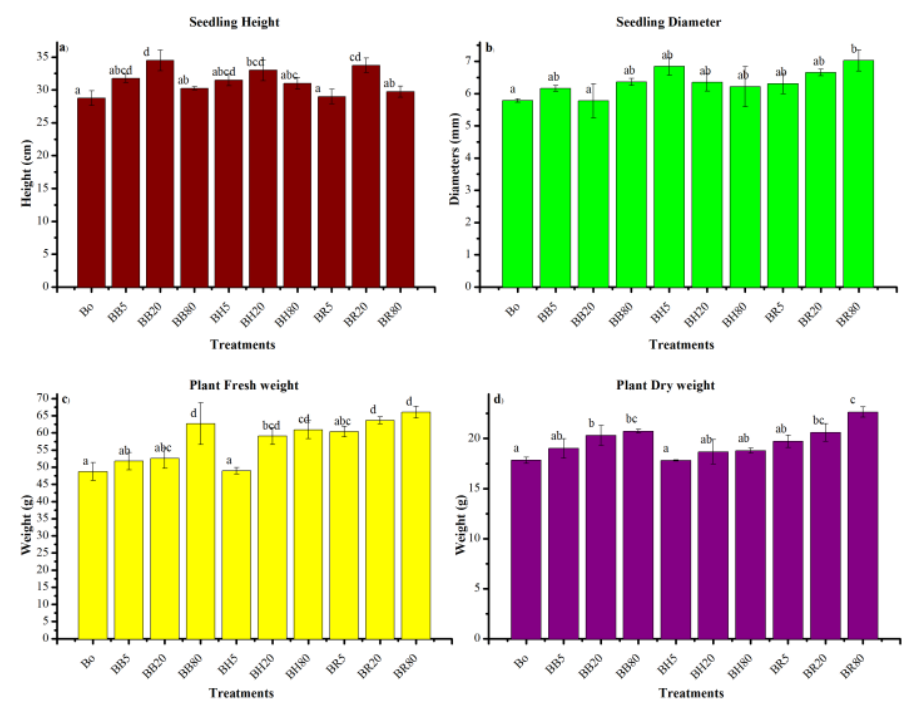

Figure 4. Comparison of above ground parameters of seedlings treated with different biochars, a) seedling height b) seedling basal diameter, c) plant fresh weight, d) dry weight.

Treatments include; control as $B$, bamboo biochar as $(B B ; 5,20$ and 80 representing different doses $\mathrm{g} \mathrm{kg^{-1 }}$ of soil), hardwood biochar as (BH; 5, 20 and 80 representing different doses $\mathrm{g} \mathrm{kg}^{-1}$ of soil), rice straw biochar as (BR; 5, 20 and 80 representing different doses $\mathrm{g} \mathrm{kg}^{-1}$ of soil).

Different letters indicate significant difference $(P \leq 0.05)$ among different treatments with error bars
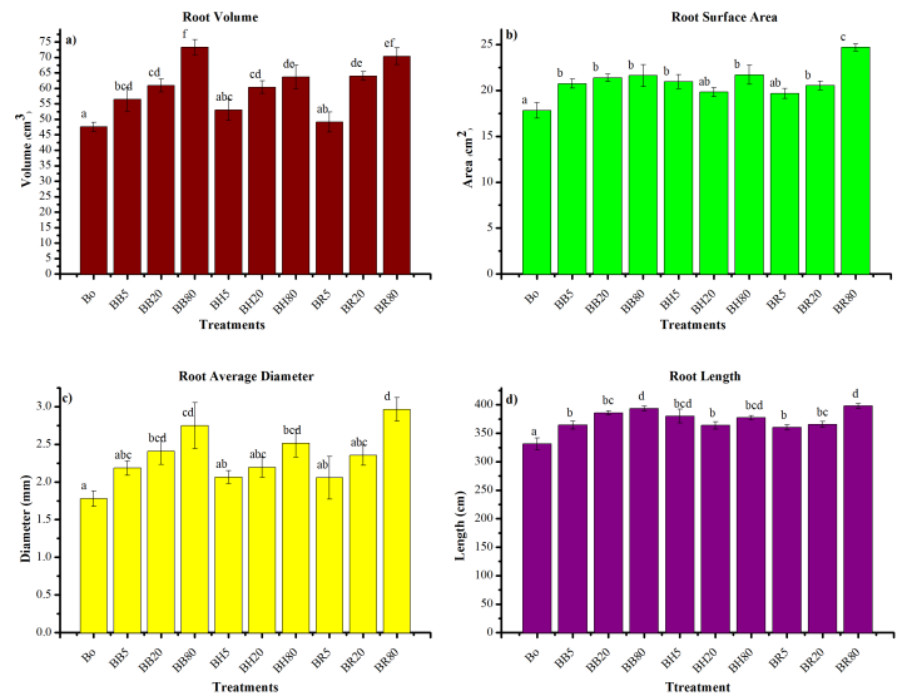

Figure 5. Comparison of root morphological features among all BC treatments; a) Root volume $\left.\left(\mathrm{cm}^{3}\right), b\right)$ Root surface area $\left.\left(\mathrm{cm}^{2}\right), c\right)$ Root average diameter $\left.(\mathrm{mm}), d\right)$ Root length $(\mathrm{cm})$.

Treatments include; control as Bo, bamboo biochar as (BB; 5, 20 and 80 representing different doses $g \mathrm{Kg}^{-1}$ of soil), hardwood biochar as (BH; 5, 20 and 80 representing different doses $\mathrm{g} \mathrm{Kg}^{-1}$ of soil), rice straw biochar as (BR; 5, 20 and 80 representing different doses $g \mathrm{Kg}^{-1}$ of soil) Different letters indicate significant difference $(P \leq 0.05)$ among different treatments with error bars 
Root surface area of the seedlings was not much influenced within the different BC ammendments, although there was significant difference among the seedlings treated with Bo, BH20 and BR5 compared to all other treatment combination with maximum value in BR80 (Fig. 5b). For average diameter, seedlings treated with BB5, BH5, BH20, $\mathrm{BR} 5$, and BR20 had no significant difference than that of Bo and under BR80 amendments, seedlings had the highest roots diameter followed by BB80 with significant difference compared to Bo (Fig. 5c). Similarly, BC treated seedlings significantly increased the root length compared to Bo but between different BCs treatment combinations, there was no significant difference, except BB80 and BR80 (Fig. 5d).

\section{Discussion}

\section{Effects of biochars amendments on physiochemical properties of soil}

Various studies have demonstrated that $\mathrm{BC}$ application into the soil can promotes the plant growth by improving physiochemical properties of soil like essential nutrients (NPK), pH and cation exchange capacity (Lehmann et al., 2011). Therefore, the responses of root traits to $\mathrm{BC}$ incorporated soil depend on soil type and $\mathrm{BC}$ (Macdonald et al., 2014). In addition, BC often applied with fertilizer to the soil has interactively regulated the root growth of the plants (Alburquerque et al., 2015). The incorporation of all three $\mathrm{BCs}$ increased soil $\mathrm{pH}$, however the rise in $\mathrm{pH}$ was evident under higher dose of BB and BR (Fig. 2a) because both of these two BCs have higher $\mathrm{pH}$ compared to $\mathrm{BH}$ (Table 1). Alkaline nature of $\mathrm{BCs}$ (BB and $\mathrm{BR}$ ) to soil has resulted increase in $\mathrm{pH}$. Our results are in the line with the previous findings where incorporation of alkaline BC with higher dose raised the soil $\mathrm{pH}$ (Ishii and Kadoya, 1994). Moreover, the liming effect of BR was generally greater than that of other two types of $\mathrm{BCs}(\mathrm{BB}$ and $\mathrm{BH})$; our findings are in the agreement with the previous study on acidic soil (Wang et al., 2009). Therefore, the $\mathrm{pH}$ of $\mathrm{BC}$ must be taken into account in order to control liming effects and consequently can be applied to acidic soil to raise the soil $\mathrm{pH}$. In the current study the soil $\mathrm{pH}$ of Bo was 4.68, consequently, lower soil $\mathrm{pH}$ (highly acidic) always reduces the cation exchange capacity and also the bio-availability of nutrients (Verheijen et al., 2010). The rise in soil $\mathrm{pH}$ from 4.68 to 5.27 and 5.40 under BB80 and BR80, respectively altered soil physiochemical properties (Fig. 2a) which is the agreement with numerous studies (Vaccari et al., 2011; Yuan and Xu, 2011). Our results were further justified by Yuan and $\mathrm{Xu}$ (2011) that incorporation of BC not ameliorates soil acidity and but also improves the soil fertility. The total Nitrogen (TN) contents were highest in BH80 compared to other types of BCs (BB and BR). A potential mechanism for increased Nitrogen retention in soils mixed with BCs is the increased nitrates recycling because of higher availability of $C$ (Verheijen et al., 2010). The increase in SOM and total $\mathrm{N}$ following $\mathrm{BC}$ application is similar to previous findings where soil $\mathrm{C}$ and $\mathrm{N}$ were increased because of application of different types of BCs (Stavi and Lal, 2013; Angst et al., 2014). Consequently, under BB80 and BR80 treatments, greater values were observed for available P compared to BH80 (Fig. 3d). Nevertheless, evidence suggests that BC can increase the nitrification if applied to acidic soils (Ball et al., 2010; Nelson et al., 2011). On the contrary, as described by few researchers that incorporation of $\mathrm{BC}$ to agricultural system, may decrease soil $\mathrm{N}$ just after addition, because $\mathrm{N}$ demand for agriculture crops has always been higher compared to forests plants (Tammeorg et al., 2012). At the start of our experiment 
(March, 2017) for better effect of BCs, we had applied minimal dose (10 g each pot) of NPK fertilizer to all treatments including Bo. In the view of this, earlier BCs studies have demonstrated that application of $\mathrm{BC}$ combined with fertilizers have been more effective for attaining better growth (Sarfraz et al., 2017). Besides, increased N retention under rice straw BC experiment is similar to our findings (Noguera et al., 2010). In our experiment $\mathrm{BB} 80$ and $\mathrm{BR} 80$ treatments, soil $\mathrm{pH}$ was relatively higher than that of other treatment combinations, rise in soil $\mathrm{pH}$ resulting availability of $\mathrm{P}$, because $\mathrm{pH}$ of $\mathrm{BH}$ under three levels (BH5, BH20, and $\mathrm{BH} 80$ ) was not much increased. Our these findings are in the line with the previous findings, because BCs particles not only holds the soil $\mathrm{N}$ in the form of nitrates, but also supply $\mathrm{P}$ to the soil and plant but their affect varies under different feedstocks (Prendergast-Miller et al., 2014). Additionally BC incorporation increased the extractable potassium (Ext. K) under BC amendments because $\mathrm{BC}$ is a soil conditioner which might act like a fertilizer and it contains ash which in return adds nutrients like Potassium $(\mathrm{K})$, Magnesium $(\mathrm{Mg})$, and Calcium $(\mathrm{Ca})$ to soil which in response raises the soil $\mathrm{pH}$ and provide essential nutrients to soil for better growth (Agegnehu et al., 2015).

\section{Effects of biochars amendments on morphology and biomass}

Various studies have confirmed that BC addition to soil increases the seedlings and roots growth both under natural and nursery conditions (Chan et al., 2008a; Noguera et al., 2010). Growth parameters of $F$. hodginsii seedlings under BC amended soils were improved as compared to Bo (Fig. 3) which is consistent with previous findings (Ali et al., 2017; Tayyab et al., 2018). Strong positive responses to BC additions were observed in biomass, resulting increase in plant fresh weight and height of (Fig. $4 a$ and c), which is agreement with the previous studies (Caroline et al., 2016; Seehausen et al., 2017). Because $\mathrm{BC}$ is a soil conditioner which might act like a fertilizer and provide nutrients to soil for plant growth (Agegnehu et al., 2015). The availability of primary nutrients to soil for plants (Sarfraz et al., 2017) with improved water holding capacity is attributed to the BC structure (Jeffery et al., 2011). Better water retention is the consequence of BC amended soil, which increases the water use efficiency of a plant, thus enhancing plant height and fresh/dry weight (Liang et al., 2006; Uzoma et al., 2011; Younis et al., 2015). In general, seedling growth parameters (seedling height, Biomass, root traits) varied only within the $\mathrm{BC}$ types and with the highest doses. The results obtained from the current study suggested that BC application increased the above and below ground morphological attributes (Figs. 4 and 5). Although basic soil in this study was strongly acidic ( $\mathrm{pH}$ 4.68), but the slight increase in $\mathrm{pH}$ by applying alkaline BCs (BB and BR) has resulted improvement in nutrient availability (or nutrient use efficiency) with successive growth which is in the line with the findings of Robertson et al. (2012). BCs application particularly under BB and BR (20 and $80 \mathrm{~g} \mathrm{~kg}^{-1}$ of soil) increased the root volume, surface area, total root length, and average root diameter compared to Bo (Fig. 5). However, under BH $\left(5,20,80 \mathrm{~g} \mathrm{~kg}^{-1}\right)$ the root morphological traits had greater or no significant difference compared to Bo. Previously for conifers seedling, there is no research data to compare the $\mathrm{BC}$ effects on root traits but our findings are attributed to change in the physiochemical properties of soil. Under higher dose of BCs (20 and $80 \mathrm{~g} \mathrm{~kg}^{-1}$ of soil) the improved roots morphological traits are consistent with previous studies (Razaq et al., 2017). Similar to our findings, Guo et al. (2008) reported that BC incorporation to acidic soil has been known to influence the root surface area, length, and volume of the seedlings in acidic red soil. In another study by Ishii and Kadoya 
(1994) who demonstrated that application of BC increases the plant and root biomass. Our these results were further justified by Yang et al. (2015) who confirmed at the seedling stage, incorporation of BC improves the root morphological traits because of improved water holding capacity and soil physiochemical properties ultimately effects the root growth (Piccolo et al., 1996). Even though there are only few other comparable studies like, review by Lehmann et al. (2011) has demonstrated that BC has positive effect on root growth. BC application has significant effects on morphological traits and functioning of roots because its particles contact the roots directly for uptake of nutrients. The increased root length in our experiment (Fig. 5d) suggests that BC application increases the plant rhizosphere enabling plants to absorb water and nutrients freely (Prendergast-Miller et al., 2014). BC addition to soil, also enhances the microbe's community, reduces soil pathogen, and boosts plant defenses which consequently improve the seedlings health with minimal damage to the environment (Elad et al., 2010). Overall, these findings demonstrate the potential of BC application for improved seedling growth.

\section{Conclusion}

Our results confirmed that positive response of $F$. hodginsii biomass and root growth was attributed to $\mathrm{BC}$ amendment at seedling stage because it can serve as a direct nutrient supply through addition of soluble $\mathrm{P}$ and biochar- $\mathrm{N}$ retention (PrendergastMiller et al., 2014). But the positive effects varied under different level and BC feedstock used. The seedlings treated with BR80, BB80, and BH80 attained 36\%, 29\%, and $25 \%$ biomass, respectively compared to Bo. Our these findings are in consistent with previous studies suggesting increase in biomass of woody plants summarized by a meta-analysis with an average $41 \%$ increase in biomass (Thomas and Gale, 2015). This is the first report on the effect of $\mathrm{BC}$ application on $F$. hodginsii morphological traits of root. Biochar application improved the physiochemical properties of soil, biomass and roots morphological attributes at seedling stage in greenhouse experiment. The current experiment was focused on the influence of different BCs application on $F$. hodginsii root traits at the early stage in a pot experiment. It is suggested that further field studies are needed to assess the complete effect of $\mathrm{BC}$ application on root system changes, soil microbial and nutrients dynamics.

Acknowledgements. The current project was funded by Science and Technology Major Projects of Fujian Province [2018NZ0001-1], Fujian Agriculture and Forestry University Science and Technology Development Fund Project [KF2015085], and Fujian Seedling Science and Technology Research Project, P. R. China.

\section{REFERENCES}

[1] Adams, F. (1984): Crop response to lime in the southern United States. - Soil acidity liming: 211-265.

[2] Agegnehu, G., Bass, A. M., Nelson, P. N., Muirhead, B., Wright, G., Bird, M. I. (2015): Biochar and biochar-compost as soil amendments: Effects on peanut yield, soil properties and greenhouse gas emissions in tropical North Queensland, Australia. - Agric Ecosyst Environ. https://doi.org/10.1016/j.agee.2015.07.027. 
[3] Alburquerque, J. A., Cabello, M., Avelino, R., Barrón, V., del Campillo, M. C., Torrent, J. (2015): Plant growth responses to biochar amendment of Mediterranean soils deficient in iron and phosphorus. - J Plant Nutr Soil Sci 178: 567-575.

[4] Alexander, L. V., Zhang, X., Peterson, T. C., Caesar, J., Gleason, B., Tank, A. M. G. K., Haylock, M., Collins, D., Trewin, B., Rahimzadeh, F. (2006): Global observed changes in daily climate extremes of temperature and precipitation. - J Geophys Res Atmos 111.

[5] Ali, S., Rizwan, M., Qayyum, M. F., Ok, Y. S., Ibrahim, M., Riaz, M., Arif, M. S., Hafeez, F., Al-Wabel, M. I., Shahzad, A. N. (2017): Biochar soil amendment on alleviation of drought and salt stress in plants: a critical review. - Environ Sci Pollut Res 24: 12700-12712. https://doi.org/10.1007/s11356-017-8904-x.

[6] Angst, T. E., Six, J., Reay, D. S., Sohi, S. P. (2014): Impact of pine chip biochar on trace greenhouse gas emissions and soil nutrient dynamics in an annual ryegrass system in California. - Agric Ecosyst Environ 191: 17-26.

[7] Ball, P. N., MacKenzie, M. D., DeLuca, T. H., Montana, W. E.( 2010): Wildfire and charcoal enhance nitrification and ammonium-oxidizing bacterial abundance in dry montane forest soils. - J Environ Qual 39: 1243-1253.

[8] Baquy, M., Li, J.-Y., Xu, C.-Y., Mehmood, K., Xu, R.-K. (2017): Determination of critical pH and $\mathrm{Al}$ concentration of acidic Ultisols for wheat and canola crops. - Solid Earth 8: 149-159.

[9] Brennan, A., Jiménez, E. M., Puschenreiter, M., Alburquerque, J. A., Switzer, C. (2014): Effects of biochar amendment on root traits and contaminant availability of maize plants in a copper and arsenic impacted soil. - Plant Soil 379: 351-360.

[10] Caroline, A., Debode, J., Vandecasteele, B., D’Hose, T., Cremelie, P., Haegeman, A., Ruttink, T., Dawyndt, P., Maes, M. (2016): Biological, physicochemical and plant health responses in lettuce and strawberry in soil or peat amended with biochar. - Appl Soil Ecol 107: 1-12.

[11] Chan, K. Y., Van Zwieten, L., Meszaros, I., Downie, A., Joseph, S. (2008a): Using poultry litter biochars as soil amendments. - Soil Res 46: 437-444.

[12] Chan, K. Y., Van Zwieten, L., Meszaros, I., Downie, A., Joseph, S. (2008b): Agronomic values of greenwaste biochar as a soil amendment. - Soil Res 45: 629-634.

[13] Clothier, B. E., Green, S. R. (1997): Roots: the big movers of water and chemical in soil. - Soil Sci 162: 534-543.

[14] Ding, M., Meng, K., Fan, Q., Tan, W., Liao, W., Chen, S. (2017): Development and Validation of EST-SSR Markers for Fokienia hodginsii (Cupressaceae). - Appl Plant Sci 5: 1600152. https://doi.org/10.3732/apps.1600152.

[15] Edwards, E. J., Benham, D. G., Marland, L. A., Fitter, A. H. (2004): Root production is determined by radiation flux in a temperate grassland community. - Glob Chang Biol 10: 209227.

[16] Eissenstat, D. M., Yanai, R. D. (1997): The ecology of root lifespan, in: Advances in Ecological Research. - Elsevier, pp. 1-60.

[17] Elad, Y., David, D. R., Harel, Y. M., Borenshtein, M., Kalifa, H. B., Silber, A., Graber, E. R. (2010): Induction of systemic resistance in plants by biochar, a soil-applied carbon sequestering agent. - Phytopathology 100: 913-921.

[18] Gaskin, J. W., Steiner, C., Harris, K., Das, K. C., Bibens, B. (2008): Effect of low-temperature pyrolysis conditions on biochar for agricultural use. - Trans ASABE 51: 2061-2069.

[19] Guo, D., Xia, M., Wei, X., Chang, W., Liu, Y., Wang, Z. (2008): Anatomical traits associated with absorption and mycorrhizal colonization are linked to root branch order in twenty-three Chinese temperate tree species. - New Phytol 180: 673-683.

[20] Haynes, R. J., Mokolobate, M. S. (2001): Amelioration of Al toxicity and P deficiency in acid soils by additions of organic residues: a critical review of the phenomenon and the mechanisms involved. - Nutr Cycl agroecosystems 59: 47-63.

[21] Ishii, T., Kadoya, K. (1994): Effects of charcoal as a soil conditioner on citrus growth and vesicular-arbuscular mycorrhizal development. - J Japanese Soc Hortic Sci 63: 529-535.

[22] Jeffery, S., Verheijen, F. G. A., van der Velde, M., Bastos, A. C. (2011): A quantitative review of the effects of biochar application to soils on crop productivity using meta-analysis. - Agric 
Ecosyst Environ 144: 175-187. https://doi.org/10.1016/ j.agee.2011.08.015.

[23] Keith, A., Singh, B., Dijkstra, F. A. (2015): Biochar reduces the rhizosphere priming effect on soil organic carbon. - Soil Biol Biochem 88: 372-379.

[24] Lal, R. (2015): Restoring soil quality to mitigate soil degradation. - Sustainability 7: 5875-5895.

[25] Lehmann, J., Gaunt, J., Rondon, M. (2006): Bio-char sequestration in terrestrial ecosystems-a review. - Mitig Adapt Strateg Glob Chang 11: 403-427.

[26] Lehmann, J., Rillig, M. C., Thies, J., Masiello, C. A., Hockaday, W. C., Crowley, D. (2011): Biochar effects on soil biota-a review. - Soil Biol Biochem 43: 1812-1836.

[27] Li, Y., Hu, S., Chen, J., Müller, K., Li, Y., Fu, W., Lin, Z., Wang, H. (2018): Effects of biochar application in forest ecosystems on soil properties and greenhouse gas emissions: a review. $-\mathbf{J}$ Soils Sediments 18: 546-563. https://doi.org/10.1007/s11368-017-1906-y.

[28] Liang, B., Lehmann, J., Solomon, D., Kinyangi, J., Grossman, J., O'neill, B., Skjemstad, J. O., Thies, J., Luizao, F. J., Petersen, J. (2006): Black carbon increases cation exchange capacity in soils. - Soil Sci Soc Am J 70: 1719-1730.

[29] Luu, N. D. T., Thomas, P. I. (2000): Conifers of Vietnam. Foreign languages pub. - Hou Hanoi.

[30] Macdonald, L. M., Farrell, M., Van Zwieten, L., Krull, E. S. (2014): Plant growth responses to biochar addition: an Australian soils perspective. - Biol Fertil soils 50: 1035-1045.

[31] Nelson, N. O., Agudelo, S. C., Yuan, W., Gan, J. (2011): Nitrogen and phosphorus availability in biochar-amended soils. - Soil Sci 176: 218-226.

[32] Nguyen, D. Q., Phan, T. P. H., Dao, V. T. (2015): Effect of storage time and pretreatment on seed germination of the threatened coniferous species Fokienia hodginsii. - Plant Species Biol 30: 291-296. https://doi.org/10.1111/1442-1984.12062.

[33] Nie, M., Lu, M., Bell, J., Raut, S., Pendall, E. (2013): Altered root traits due to elevated CO2: a meta-analysis. - Glob Ecol Biogeogr 22: 1095-1105.

[34] Noguera, D., Rondón, M., Laossi, K.-R., Hoyos, V., Lavelle, P., de Carvalho, M. H. C., Barot, S. (2010): Contrasted effect of biochar and earthworms on rice growth and resource allocation in different soils. - Soil Biol Biochem 42: 1017-1027.

[35] Osborn, T. (2004): Preparation and implementation of a strategy for the management of Fokienia hodginsii in Vietnam by 2008. - FFI, Hanoi.

[36] Paluch, G. E. (2009): Characterization of botanical terpene activity in arthropods.

[37] Pansu, M., Gautheyrou, J. (2007): Handbook of soil analysis: mineralogical, organic and inorganic methods. - Springer Science \& Business Media.

[38] Piccolo, A., Pietramellara, G., Mbagwu, J. S. C. (1996): Effects of coal derived humic substances on water retention and structural stability of Mediterranean soils. - Soil Use Manag 12: 209-213.

[39] Prendergast-Miller, M. T., Duvall, M., Sohi, S. P. (2014): Biochar-root interactions are mediated by biochar nutrient content and impacts on soil nutrient availability. - Eur J Soil Sci 65: 173185. https://doi.org/10.1111/ejss.12079.

[40] Prendergast-Miller, M. T., Duvall, M., Sohi, S. P. (2014): Biochar-root interactions are mediated by biochar nutrient content and impacts on soil nutrient availability. - Eur J Soil Sci 65: 173-185.

[41] Razaq, M., Salahuddin, Shen, H. L., Sher, H., Zhang, P. (2017): Influence of biochar and nitrogen on fine root morphology, physiology, and chemistry of Acer mono. - Sci Rep 7: 1-11. https://doi.org/10.1038/s41598-017-05721-2.

[42] Reibe, K., Götz, K.-P., Roß, C.-L., Döring, T. F., Ellmer, F., Ruess, L. (2015): Impact of quality and quantity of biochar and hydrochar on soil Collembola and growth of spring wheat. - Soil Biol Biochem 83: 84-87.

[43] Reverchon, F., Flicker, R. C., Yang, H., Yan, G., Xu, Z., Chen, C., Bai, S. H., Zhang, D. (2014): Changes in $\delta 15 \mathrm{~N}$ in a soil-plant system under different biochar feedstocks and application rates. - Biol Fertil soils 50: 275-283. 
[44] Rillig, M. C., Wagner, M., Salem, M., Antunes, P. M., George, C., Ramke, H.-G., Titirici, M.M., Antonietti, M. (2010): Material derived from hydrothermal carbonization: effects on plant growth and arbuscular mycorrhiza. - Appl Soil Ecol 45: 238-242.

[45] Robertson, S. J., Rutherford, P. M., López-Gutiérrez, J. C., Massicotte, H. B. (2012): Biochar enhances seedling growth and alters root symbioses and properties of sub-boreal forest soils. Can J Soil Sci 92: 329-340. https://doi.org/10.4141/cjss2011-066.

[46] Sarfraz, R., Shakoor, A., Abdullah, M., Arooj, A., Hussain, A., Xing, S. (2017): Impact of integrated application of biochar and nitrogen fertilizers on maize growth and nitrogen recovery in alkaline calcareous soil. $\quad-$ Soil Sci Plant Nutr 63: 488-498. https://doi.org/10.1080/00380768.2017.1376225.

[47] Sarfraz, R., Li, S., Yang, W., Zhou, B., Xing, S. (2019): Assessment of physicochemical and nutritional characteristics of waste mushroom substrate biochar under various pyrolysis temperatures and times. - Sustain. 11: 1-14.

[48] Seehausen, M., Gale, N., Dranga, S., Hudson, V., Liu, N., Michener, J., Thurston, E., Williams, C., Smith, S., Thomas, S. (2017): Is There a Positive Synergistic Effect of Biochar and Compost Soil Amendments on Plant Growth and Physiological Performance? - Agronomy 7: 13. https://doi.org/10.3390/agronomy7010013.

[49] Stavi, I., Lal, R. (2013): Agroforestry and biochar to offset climate change: a review. - Agron Sustain Dev 33: 81-96.

[50] Tammeorg, P., Brandstaka, T., Simojoki, A., Helenius, J. (2012): Nitrogen mineralisation dynamics of meat bone meal and cattle manure as affected by the application of softwood chip biochar in soil. - Earth Environ Sci Trans R Soc Edinburgh 103: 19-30.

[51] Tarin, M. W., Nizami, S. M., Jundong, R., Lingyan, C., You, H., Farooq, T. H., Gilani, M. M., Ifthikar, J., Tayyab, M., Zheng, Y. (2017): Range vegetation analysis of Kherimurat Scrub Forest, Pakistan. - Int J Dev Sustain 66: 2186-8662.

[52] Tarin, M. W. K., Fan, L., Tayyab, M., Sarfraz, R., Chen, L., He, T., Rong, J., Chen, L., Zheng, Y. (2019): Effects of Bamboo Biochar Amendment on the Growth and Physiological Characteristics of Fokienia Hodginsii. - Appl Ecol Environ Res 16: 8055-8074. https://doi.org/10.15666/aeer/1606_80558074.

[53] Tayyab, M., Islam, W., Khalil, F., Ziqin, P., Caifang, Z., Arafat, Y., Hui, L., Rizwan, M., Ahmad, K., Waheed, S., Tarin, M. W. K., Hua, Z. (2018): Biochar: an efficient way to manage low water availability in plants. - Appl Ecol Environ Res 16: 2565-2583. https://doi.org/10.15666/aeer/1603_25652583.

[54] Thomas, S. C., Gale, N. (2015): Biochar and forest restoration: a review and meta-analysis of tree growth responses. - New For 46: 931-946.

[55] Tonks, A. J., Aplin, P., Beriro, D. J., Cooper, H., Evers, S., Vane, C. H., Sjögersten, S. (2017): Impacts of conversion of tropical peat swamp forest to oil palm plantation on peat organic chemistry, physical properties and carbon stocks. - Geoderma 289: 36-45.

[56] Topoliantz, S., Ponge, J.-F., Ballof, S. (2005): Manioc peel and charcoal: a potential organic amendment for sustainable soil fertility in the tropics. - Biol Fertil Soils 41: 15-21.

[57] Uzoma, K. C., Inoue, M., Andry, H., Fujimaki, H., Zahoor, A., Nishihara, E. (2011): Effect of cow manure biochar on maize productivity under sandy soil condition. - Soil use Manag 27: 205-212.

[58] Vaccari, F. P., Baronti, S., Lugato, E., Genesio, L., Castaldi, S., Fornasier, F., Miglietta, F. (2011): Biochar as a strategy to sequester carbon and increase yield in durum wheat. - Eur $\mathbf{J}$ Agron 34: 231-238.

[59] Van de voorde, T. F. J., van Noppen, F., Nachenius, R. W., Prins, W., Mommer, L., Van Groenigen, J.-W., Bezemer, T. M. (2014): Biochars produced from individual grassland species differ in their effect on plant growth. - Basic Appl Ecol 15: 18-25.

[60] Vanek, S. J., Lehmann, J. (2015): Phosphorus availability to beans via interactions between mycorrhizas and biochar. - Plant Soil 395: 105-123. 
[61] Verheijen, F., Jeffery, S., Bastos, A. C., Van Der Velde, M., Diafas, I. (2010): Biochar application to soils: a critical review of effects on soil properties, processes and functions. - JRC Scientific and technical Report. https://doi.org/10.2788/472.

[62] Wang, N., Li, J., Xu, R. (2009): Use of agricultural by-products to study the $\mathrm{pH}$ effects in an acid tea garden soil. - Soil use Manag 25: 128-132.

[63] Wang, Y., Pan, F., Wang, G., Zhang, G., Wang, Y., Chen, X., Mao, Z. (2014): Effects of biochar on photosynthesis and antioxidative system of Malus hupehensis Rehd. seedlings under replant conditions. - Sci Hortic (Amsterdam) 175: 9-15. https://doi.org/ 10.1016/j.scienta.2014.05.029.

[64] Xu, R. K., Coventry, D. R. (2003): Soil pH changes associated with lupin and wheat plant materials incorporated in a red-brown earth soil. - Plant Soil 250: 113-119.

[65] Yang, L., Liao, F., Huang, M., Yang, L., Li, Y. (2015): Biochar improves sugarcane seedling root and soil properties under a pot experiment. - Sugar tech 17: 36-40.

[66] Younis, U., Athar, M., Malik, S. A., Raza Shah, M., Mahmood, S. (2015): Biochar impact on physiological and biochemical attributes of spinach Spinacia oleracea (L.) in nickel contaminated soil. - Glob J Environ Sci Manag 1: 245-254.

[67] Yuan, J. H., Xu, R. K. (2011): The amelioration effects of low temperature biochar generated from nine crop residues on an acidic Ultisol. - Soil Use Manag 27: 110-115. https://doi.org/10.1111/j.1475-2743.2010.00317.x.

\section{APPENDIX}

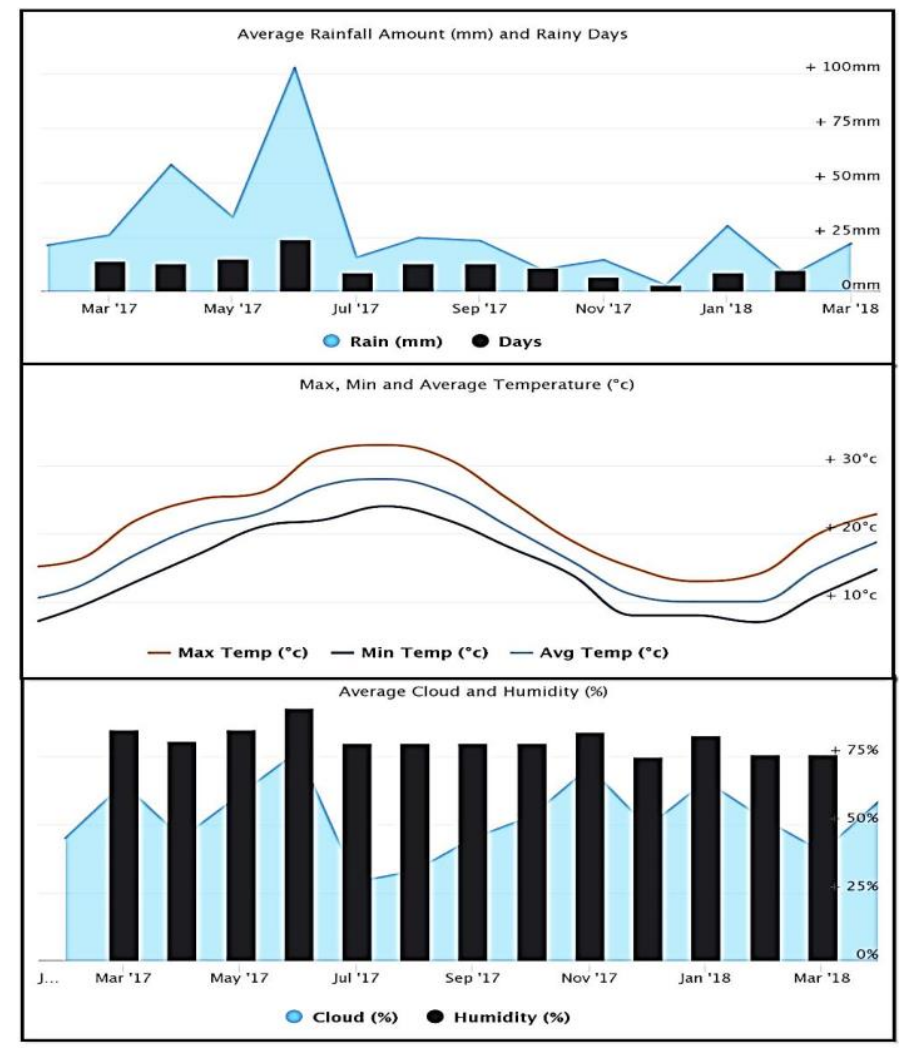

A-1. One-year metrological information of study area, during the entire experiment period (Ref: https://www.worldweatheronline.com) 